in vivo $34: 2705-2709$ (2020)

doi:10.21873/invivo.12091

\title{
Pre-operative Seizures in Patients With Single Brain Metastasis Treated With Resection Plus Whole-Brain Irradiation and a Boost
}

\author{
DIRK RADES ${ }^{1}$, JASPAR WITTELER ${ }^{1}$, TROELS W. KJAER ${ }^{2}$, SOEREN TVILSTED $^{3}$ and STEVEN E. SCHILD ${ }^{4}$ \\ ${ }^{1}$ Department of Radiation Oncology, University of Lübeck, Lübeck, Germany; \\ ${ }^{2}$ Neurological Department, Zealand University Hospital, Roskilde, Denmark; \\ ${ }^{3}$ Research Projects and Clinical Optimization, Zealand University Hospital, Koege, Denmark; \\ ${ }^{4}$ Department of Radiation Oncology, Mayo Clinic, Scottsdale, AZ, U.S.A.
}

\begin{abstract}
Background/Aim: Seizures can be the initial symptom of brain metastases. This study investigated pretreatment seizures in patients with a single lesion. Patients and Methods: Pre-operative seizures were analyzed in 104 patients with a single brain metastasis receiving resection plus whole-brain irradiation and a boost. Prevalence of seizures, risk factors and associations with survival (OS) were evaluated. Results: Thirty patients (34.6\%) had seizures prior to neurosurgery. Significant associations between seizures and investigated characteristics were not found. However, age $\leq 61$ years showed a trend $(p=0.117)$ for increased incidence of seizures. Time from diagnosis of malignancy until neurosurgery >12 months was significantly associated with improved OS on univariate analysis ( $p=0.003)$. Trends for a positive association with OS were found for no seizures $(p=0.054)$, female gender $(p=0.066)$ and breast cancer $(p=0.098)$. On multivariate analysis, time until neurosurgery $>12$ months was independently associated $(p=0.019)$ with better $O S$, and seizures showed a trend ( $p=0.119)$ for improved OS. Conclusions: Considering the high prevalence of seizures in this cohort, regular screening and monitoring of these patients appears reasonable. This applies particularly to patients aged $\leq 61$ years.
\end{abstract}

This article is freely accessible online.

Correspondence to: Prof. Dirk Rades, MD, Department of Radiation Oncology, University of Lübeck, Lübeck, Ratzeburger Allee 160, 23562 Lübeck, Germany. Tel: +49 45150045401, Fax: +49 45150045404, e-mail: dirk.rades@uksh.de

Key Words: Brain metastasis, single lesion, seizures, neurosurgical resection, whole-brain irradiation, boost dose.
Metastasis to the brain represents a relatively common situation in adult cancer patients and is often associated with serious symptoms impairing quality of life $(1,2)$. With respect to the number of lesions, patients can be classified as having single brain metastasis, oligo-metastatic disease (usually up to three lesions) or multiple brain metastases (usually more than three lesions) (2). A serious problem in patients with brain metastasis is the occurrence of seizures (3). Seizures can occur prior to the start of treatment and even be the initial symptom leading to the diagnosis of brain metastasis. Pre-treatment seizures appear much more common than seizures occurring during treatment or follow-up (3). Moreover, occurrence of seizures may be associated with the number of intracerebral lesions. However, the data reported appear conflicting. In the study of Wu et al., pre-operative seizures were significantly associated with more than two intracerebral lesions, whereas in the study of Wolpert et al., no significant association between pre-operative seizures and the number of brain metastases was observed $(4,5)$. Nevertheless, in the study of Wolpert et al., single brain metastasis was the most important risk factor for seizures in non-operated patients (5). It appears reasonable to perform separate studies in patients with single, limited numbers or multiple intracerebral lesions, as well as in patients treated with or without neurosurgical resection to properly define the role of seizures in patients with brain metastasis. This study focused on patients with a single intracerebral lesion who received resection of their metastasis followed by whole-brain irradiation (WBI) and a boost to the resection cavity.

\section{Patients and Methods}

Patients. This retrospective study investigated the role of seizures prior to neurosurgery in a series of 104 patients with a single brain metastasis from an anonymized database, who were treated with neurosurgical resection followed by WBI and a boost dose to the 
Table I. Patient characteristics.

\begin{tabular}{llc}
\hline Characteristic & No & $\begin{array}{c}\text { Number of } \\
\text { patients (\%) }\end{array}$ \\
\hline Seizures prior to neurosurgery & Yes & $68(65)$ \\
Age & $\leq 61$ Years & $36(35)$ \\
& $\geq 62$ Years & $53(51)$ \\
Gender & Female & $41(49)$ \\
& Male & $58(56)$ \\
Karnofsky performance score & $\leq 70$ & $24(23)$ \\
Primary tumor type & $\geq 80$ & $80(77)$ \\
& Breast cancer & $16(15)$ \\
& Lung cancer & $51(49)$ \\
Extracranial metastatic spread & Colorectal cancer & $10(10)$ \\
\multirow{3}{*}{ Time from diagnosis of malignancy } & Other tumors & $27(26)$ \\
until neurosurgery & No & $85(82)$ \\
& Yes & $19(18)$ \\
& $\leq 12$ Months & $52(50)$ \\
& $>12$ Months & $52(50)$ \\
\hline
\end{tabular}

resection cavity between 1999 and 2017. WBI was performed either with $20 \mathrm{~Gy}$ in 5 fractions $(n=66)$ or $30 \mathrm{~Gy}$ in 10 fractions $(n=38)$. The boost included the additional delivery of one of the following: $15 \mathrm{~Gy}$ in 5 fractions $(n=53), 10 \mathrm{~Gy}$ in 5 fractions $(n=36), 20$ Gy in 10 fractions $(n=7), 9$ Gy in 3 fractions $(n=5)$ or 6 Gy in 2 fractions $(n=3)$. The study was approved by the corresponding Ethics Committee at the University of Lübeck, Lübeck, Germany on the $3^{\text {rd }}$ of April 2020 (reference number 20-120A). Three issues were evaluated in this study: the prevalence of seizures prior to neurosurgery, potential risk factors for seizures, and a potential association between seizures and overall survival (OS).

Variables and statistical analyses. Six pre-treatment characteristics (Table I), including age ( $\leq 61$ vs. $\geq 62$ years; median age $=61$ years $)$, gender, Karnofsky performance score $(\leq 70 v s . \geq 80$; median performance score $=80$ ), type of primary tumor (breast cancer, lung cancer, colorectal cancer and other types), extracranial metastatic spread (no vs. yes) and time from diagnosis of malignancy until neurosurgery $(\leq 12 \mathrm{vs} .>12$ months, median time $=12.5$ months), were investigated for associations with seizures prior to neurosurgery using the Chi-square test. All $p$-values $<0.05$ were rated significant, and $p$-values $<0.12$ indicated a trend.

These six characteristics and seizures prior to neurosurgery (no $v s$. yes) were also evaluated with respect to OS. Time to death was referenced from the day of neurosurgical resection. For univariate analyses of OS, we used the Kaplan-Meier method and the log-rank test. Characteristics being significant $(p<0.05)$ or showing a trend $(p<0.12)$ were additionally included in Cox proportional hazard ratio to investigate those characteristics for independence. The software used for performing statistical analyses was JMP 14 (SAS institute inc., Cary, NC, U.S.A.).

\section{Results}

In the cohort of 104 patients, 36 patients had seizures prior to neurosurgery corresponding to a prevalence of $34.6 \%$. Twenty-six of these patients had seizures without other
Table II. Associations between the investigated characteristics and occurrence of seizures prior to neurosurgery.

\begin{tabular}{lrr}
\hline Characteristic & $\begin{array}{c}\text { Patients with } \\
\text { seizures (\%) }\end{array}$ & $p$-Value \\
\hline Age & & \\
$\quad \leq 61$ Years & $23(43.3)$ & 0.117 \\
$\quad \geq 62$ Years & $13(25.5)$ & \\
Gender & $17(37.0)$ & 0.297 \\
$\quad$ Female & $19(32.8)$ & \\
$\quad$ Male & & \\
Karnofsky performance score & $5(20.8)$ & 0.192 \\
$\quad \leq 70$ & $31(38.8)$ & \\
$\quad \geq 80$ & & \\
Primary tumor type & $5(31.3)$ & 0.703 \\
$\quad$ Breast cancer & $15(29.4)$ & \\
$\quad$ Lung cancer & $5(50.0)$ & \\
$\quad$ Colorectal cancer & $11(40.7)$ & \\
$\quad$ Other tumors & & \\
Extracranial metastatic spread & $26(30.6)$ & 0.143 \\
$\quad$ No & $10(53.6)$ & \\
$\quad$ Yes & & \\
Time from diagnosis of malignancy & & \\
until neurosurgery & & \\
$\quad \leq 12$ Months & $15(28.8)$ & \\
$>12$ Months & $21(40.4)$ & \\
$\quad$ & &
\end{tabular}

symptoms, and 10 patients had at least one other symptom including motor deficits, dysarthria, cognitive deficits and headache. A significant association between occurrence of pre-operative seizures and one of the six investigated characteristics was not found. A trend was shown for age $\leq 61$ years $(p=0.117)$. The results of the investigation with respect to potential associations between patient characteristics and seizures prior to neurosurgery are summarized in Table II.

When investigating the potential associations of the seven characteristics including pre-operative seizures with OS, the time from diagnosis of malignancy until neurosurgery achieved significance ( $p=0.003$ ) on univariate analysis (Table III). A time period of $>12$ months was associated with improved OS. In addition, trends for better OS were found for lack of seizures prior to neurosurgery ( $p=0.054$, Figure 1$)$, female gender $(p=0.066)$ and breast cancer $(p=0.098)$. These four characteristics were subsequently evaluated for independence with a Cox proportional hazard model (Table IV). In this multivariate analysis, a time from diagnosis of malignancy until neurosurgery of $>12$ months was significant for improved OS $(p=0.019)$, and seizures prior to neurosurgery showed a trend for better OS $(p=0.119)$.

\section{Discussion}

Of patients developing brain metastases, those with a single lesion generally have better prognoses than patients with 
Table III. Survival rates up to 24 months following neurosurgical resection (univariate analysis).

\begin{tabular}{|c|c|c|c|c|c|c|}
\hline Characteristic & & $\begin{array}{l}\text { At } 6 \text { months } \\
\qquad \%)\end{array}$ & $\begin{array}{c}\text { At } 12 \text { months } \\
(\%)\end{array}$ & $\begin{array}{l}\text { At } 18 \text { months } \\
(\%)\end{array}$ & $\begin{array}{c}\text { At } 24 \text { months } \\
(\%)\end{array}$ & $p$-Value* \\
\hline \multirow[t]{2}{*}{ Seizures prior to neurosurgery } & No & 75 & 57 & 44 & 34 & \multirow[t]{2}{*}{0.054} \\
\hline & Yes & 81 & 72 & 58 & 58 & \\
\hline \multirow[t]{2}{*}{ Age } & $\leq 61$ Years & 77 & 65 & 50 & 43 & \multirow[t]{2}{*}{0.415} \\
\hline & $\geq 62$ Years & 76 & 58 & 47 & 41 & \\
\hline \multirow[t]{2}{*}{ Gender } & Female & 83 & 69 & 60 & 53 & \multirow[t]{2}{*}{0.066} \\
\hline & Male & 72 & 56 & 40 & 34 & \\
\hline \multirow[t]{2}{*}{ Karnofsky performance score } & $\leq 70$ & 67 & 44 & 38 & 38 & \multirow[t]{2}{*}{0.198} \\
\hline & $\geq 80$ & 80 & 67 & 53 & 44 & \\
\hline \multirow[t]{4}{*}{ Primary tumor type } & Breast cancer & 88 & 81 & 66 & 57 & \multirow[t]{4}{*}{0.098} \\
\hline & Lung cancer & 75 & 52 & 49 & 39 & \\
\hline & Colorectal cancer & 40 & 40 & 30 & 30 & \\
\hline & Other tumors & 89 & 76 & 44 & 44 & \\
\hline \multirow[t]{2}{*}{ Extracranial metastatic spread } & No & 81 & 65 & 50 & 42 & \multirow[t]{2}{*}{0.689} \\
\hline & Yes & 58 & 46 & 46 & 46 & \\
\hline \multirow{2}{*}{$\begin{array}{l}\text { Time from diagnosis of malignancy } \\
\text { until neurosurgery }\end{array}$} & $\leq 12$ Months & 69 & 46 & 33 & 23 & \multirow[t]{2}{*}{0.003} \\
\hline & $>12$ Months & 85 & 77 & 64 & 60 & \\
\hline
\end{tabular}

*The $p$-values were obtained from the the log-rank test and refer to the entire period of follow up. Bold value indicates statistical significance.

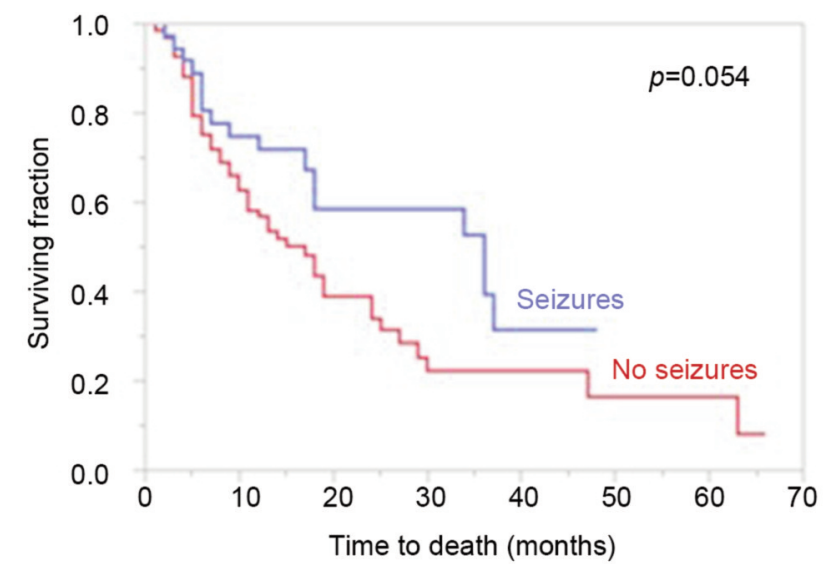

Figure 1. Kaplan-Meier curves related to seizures $(n=36)$ or no seizures $(n=68)$ prior to neurosurgery.

multiple lesions (2). Several options exist for the treatment of single brain metastasis including neurosurgery, radiosurgery, WBI and combinations of these modalities. In 1987, a retrospective study of 85 patients compared resection alone to resection plus WBI and found that the combined approach resulted in significantly better 1-year local control and median survival (6). In 1998, a randomized trial of 95 patients was published that found significantly better local control and intracerebral control at 1 year for resection plus WBI when compared to resection alone (7). These results did not lead to improved median OS, although patients receiving WBI were less likely to die of neurologic causes. However, the addition of WBI to
Table IV. Multivariate analysis of survival using the Cox proportional hazard model.

\begin{tabular}{lccc}
\hline Characteristic & Hazard ratio & $\begin{array}{c}95 \% \text { Confidence } \\
\text { interval }\end{array}$ & $p$-Value \\
\hline $\begin{array}{l}\text { Seizures prior to } \\
\text { neurosurgery }\end{array}$ & 1.56 & $0.89-2.86$ & 0.119 \\
$\begin{array}{l}\text { Gender } \\
\text { Primary tumor type } \\
\begin{array}{l}\text { Time from diagnosis } \\
\text { of malignancy until }\end{array}\end{array}$ & 1.25 & $0.72-2.21$ & 0.435 \\
neurosurgery & 1.95 & $0.96-1.13$ & 0.269 \\
& & $1.11-3.47$ & $\mathbf{0 . 0 1 9}$ \\
\hline
\end{tabular}

Bold value indicates statistical significance.

resection can lead to a significant increase of post-treatment cognitive deficits, which was reported for patients treated with radiosurgery plus WBI for 1-3 brain metastases $(8,9)$. With modern approaches including hippocampus-sparing WBI and administration of memantine, the risk of cognitive decline can be significantly reduced $(10,11)$. Thus, resection plus WBI can be considered an appropriate treatment for patients with a single brain metastasis. The outcomes after resection plus WBI can be further improved with the addition of a radiation boost to the resection cavity. In a retrospective study of 195 patients with a single lesion, resection plus WBI and a boost was superior to resection plus WBI without a boost with respect to local control of the resected metastasis (12). OS rates, however, were not significantly different. Local control is an important 
endpoint, since an intracerebral recurrence is often associated with neuro-cognitive deficits and impairment of the patients' quality of life (13-15). Therefore, resection plus WBI and a radiation boost appears preferable to resection plus WBI without a boost.

The present study focused on patients with a single lesion who received the treatment regimen including a radiation boost. It evaluated the prevalence of pre-operative seizures, risk factors for occurrence of seizures and associations with OS. The prevalence of preoperative seizures was $34.6 \%$, which was within but on the top end of the range of $12-35 \%$ reported in the literature $(3,5,16,17)$. This comparably high prevalence may be explained to a certain extent by the fact that many patients $(49 \%)$ in our study were lung cancer patients. It has been previously shown by Wolpert et al. that patients with lung cancer have increased incidence of seizures (5). Moreover, in the review article of Ruda et al., lung cancer patients had the second highest prevalence of seizures of all primary tumor types (3).

In addition to the prevalence of seizures, the present study aimed to identify risk factors for pre-operative seizures. For none of the investigated characteristics, a significant association with the occurrence of seizures was observed. However, a trend was found for younger age. This finding agrees with the results of a previous study of 286 patients undergoing resection for brain metastases that also showed an inverse correlation between age and seizures prior to neurosurgery (18). The present study also investigated potential associations between pre-operative seizures and OS. In both univariate and multivariate analyses, trends for a positive correlation between seizures and OS were found. Such a correlation was not yet reported for patients with brain metastases but for patients with low-grade and high-grade gliomas $(19,20)$. In addition to preoperative seizures, a significant correlation was found between OS and the time from the diagnosis of the malignancy until neurosurgical resection of the brain metastasis. The prognostic impact of the interval between tumor diagnosis and treatment for brain metastases was previously identified in a cohort of 1,085 patients receiving WBI alone (21). This characteristic was also included in a validated survival score for patients irradiated for brain metastases $(21,22)$. This demonstrates consistency between the present study and previous data. However, the present study was performed in a retrospective cohort of patients. Thus, a risk of a hidden selection bias exists, which needs to be considered when taking note of and interpreting our results.

In conclusion, considering the high prevalence of seizures in this cohort, regular screening and monitoring of these patients appears reasonable. This applies particularly to patients aged $\leq 61$ years. Moreover, seizures showed a trend for a positive association with OS. These findings contribute to the understanding of the role of preoperative seizures in patients with a single brain metastasis.

\section{Conflicts of Interest}

The Authors state that there are no conflicts of interest related to this study.

\section{Authors' Contributions}

All Authors participated in the design of the study. D.R. and J.W. provided the data that were analyzed and interpreted by D.R. and S.E.S. D.R. and S.E.S. drafted the manuscript, which was reviewed and finally approved by the other Authors.

\section{Acknowledgements}

As part of the NorDigHealth project, the study was funded by the European Regional Development Fund through the Interreg Deutschland-Danmark program (087-1.1-18).

\section{References}

1 Siegel RL, Miller KD and Jemal A: Cancer statistics, 2020. CA Cancer J Clin 70: 7-30, 2020. PMID: 31912902. DOI: 10.3322/ caac. 21590

2 Tsao MN, Rades D, Wirth A, Lo SS, Danielson BL, Gaspar LE, Sperduto PW, Vogelbaum MA, Radawski JD, Wang JZ, Gillin MT, Mohideen N, Hahn CA and Chang EL: Radiotherapeutic and surgical management for newly diagnosed brain metastasis(es): An American Society for Radiation Oncology evidence-based guideline. Pract Radiat Oncol 2: 210-225, 2012. PMID: 25925626. DOI: 10.1016/j.prro.2011.12.004

3 Rudà R, Mo F and Pellerino A: Epilepsy in brain metastasis: an emerging entity. Curr Treat Options Neurol 22: 6, 2020. PMID: 32034533. DOI: 10.1007/s11940-020-0613-y

4 Wu A, Weingart JD, Gallia GL, Lim M, Brem H, Bettegowda C and Chaichana KL: Risk factors for preoperative seizures and loss of seizure control in patients undergoing surgery for metastatic brain tumors. World Neurosurg 104: 120-128, 2017. PMID: 28512046. DOI: 10.1016/j.wneu.2017.05.028

5 Wolpert F, Lareida A, Terziev R, Grossenbacher B, Neidert MC, Roth P, Poryazova R, Imbach L, Le Rhun E and Weller M: Risk factors for the development of epilepsy in patients with brain metastasis. Neuro Oncol pii: noz172, 2019. PMID: 31498867. DOI: 10.1093/neuonc/noz172

6 Smalley SR, Schray MF, Laws ER Jr and O'Fallon JR: Adjuvant radiation therapy after surgical resection of solitary brain metastasis: association with pattern of failure and survival. Int $\mathbf{J}$ Radiat Oncol Biol Phys 13: 1611-1616, 1987. PMID: 3117742. DOI: 10.1016/0360-3016(87)90154-4

7 Patchell RA, Tibbs PA, Regine WF, Dempsey RJ, Mohiuddin M, Kryscio RJ, Markesbery WR, Foon KA and Young B: Postoperative radiotherapy in the treatment of single metastases to the brain: a randomized trial. JAMA 280: 1485-1489, 1998. PMID: 9809728. DOI: 10.1001/jama.280.17.1485

8 Chang EL, Wefel JS, Hess KR, Allen PK, Lang FF, Kornguth DG, Arbuckle RB, Swint JM, Shiu AS, Maor MH and Meyers CA: Neurocognition in patients with brain metastases treated with radiosurgery or radiosurgery plus whole-brain irradiation: a randomised controlled trial. Lancet Oncol 10: 1037-1044, 2009. PMID: 19801201. DOI: 10.1016/S1470-2045(09)70263-3 
9 Brown PD, Jaeckle K, Ballman KV, Farace E, Cerhan JH, Anderson SK, Carrero XW, Barker FG 2nd, Deming R, Burri SH, Ménard C, Chung C, Stieber VW, Pollock BE, Galanis E, Buckner JC and Asher AL: Effect of radiosurgery alone vs radiosurgery with whole brain radiation therapy on cognitive function in patients with 1 to 3 brain metastases: A randomized clinical trial. JAMA 316: 401-409, 2016. PMID: 27458945. DOI: $10.1001 /$ jama.2016.9839

10 Gondi V, Pugh SL, Tome WA, Caine C, Corn B, Kanner A, Rowley H, Kundapur V, DeNittis A, Greenspoon JN, Konski AA, Bauman GS, Shah S, Shi W, Wendland M, Kachnic L and Mehta MP: Preservation of memory with conformal avoidance of the hippocampal neural stem-cell compartment during wholebrain radiotherapy for brain metastases (RTOG 0933): a phase II multi-institutional trial. J Clin Oncol 32: 3810-3816, 2014. PMID: 25349290. DOI: 10.1200/JCO.2014.57.2909

11 Brown PD, Pugh S, Laack NN, Wefel JS, Khuntia D, Meyers C, Choucair A, Fox S, Suh JH, Roberge D, Kavadi V, Bentzen SM, Mehta MP and Watkins-Bruner D; Radiation Therapy Oncology Group (RTOG): Memantine for the prevention of cognitive dysfunction in patients receiving whole-brain radiotherapy: a randomized, double-blind, placebo-controlled trial. Neuro Oncol 15: 1429-1437, 2013. PMID: 23956241. DOI: 10.1093/neuonc/ not114

12 Rades D, Kueter JD, Gliemroth J, Veninga T, Pluemer A and Schild SE: Resection plus whole-brain irradiation versus resection plus whole-brain irradiation plus boost for the treatment of single brain metastasis. Strahlenther Onkol 188: 143-147, 2012. PMID: 22234538. DOI: 10.1007/s00066-0110024-9

13 Aoyama H, Tago M, Kato N, Toyoda T, Kenjyo M, Hirota S, Shioura H, Inomata T, Kunieda E, Hayakawa K, Nakagawa K, Kobashi G and Shirato H: Neurocognitive function of patients with brain metastasis who received either whole brain radiotherapy plus stereotactic radiosurgery or radiosurgery alone. Int J Radiat Oncol Biol Phys 68: 1388-1395, 2007. PMID: 17674975. DOI: 10.1016/j.ijrobp.2007.03.048

14 Meyers CA, Smith JA, Bezjak A, Mehta MP, Liebmann J, Illidge T, Kunkler I, Caudrelier JM, Eisenberg PD, Meerwaldt J, Siemers R, Carrie C, Gaspar LE, Curran W, Phan SC, Miller RA and Renschler MF: Neurocognitive function and progression in patients with brain metastases treated with whole-brain radiation and motexafin gadolinium: results of a randomized phase III trial. J Clin Oncol 22: 157-165, 2004. PMID: 14701778. DOI: 10.1200/JCO.2004.05.128
15 Regine WF, Scott C, Murray K and Curran W: Neurocognitive outcome in brain metastases patients treated with acceleratedfractionation $v s$. accelerated-hyperfractionated radiotherapy: an analysis from Radiation Therapy Oncology Group Study 91-04. Int J Radiat Oncol Biol Phys 51: 711-717, 2001. PMID: 11597813. DOI: 10.1016/s0360-3016(01)01676-5

16 Rostami R, Mittal S, Rostami P, Tavassoli F and Jabbari B: Brain metastasis in breast cancer: A comprehensive literature review. J Neurooncol 127: 407-414, 2016. PMID: 26909695. DOI: $10.1007 / \mathrm{s} 11060-016-2075-3$

17 Chan V, Sahgal A, Egeto P, Schweizer T and Das S: Incidence of seizure in adult patients with intracranial metastatic disease. J Neurooncol 131: 619-624, 2017. PMID: 27878505. DOI: 10.1007/s11060-016-2335-2

18 Puri PR, Johannsson B, Seyedi JF, Halle B, Schulz M, Pedersen $\mathrm{CB}$, Kristensen BW and Poulsen FR: The risk of developing seizures before and after surgery for brain metastases. Clin Neurol Neurosurg 193: 105779, 2020. PMID: 32200217. DOI: 10.1016/j.clineuro.2020.105779

19 Lote K, Stenwig AE, Skullerud K and Hirschberg H: Prevalence and prognostic significance of epilepsy in patients with gliomas. Eur J Cancer 34: 98-102, 1998. PMID: 9624245. DOI: 10.1016/ s0959-8049(97)00374-2

20 Englot DJ, Chang EF and Vecht CJ: Epilepsy and brain tumors. Handb Clin Neurol 134: 267-285, 2016. PMID: 26948360. DOI: 10.1016/B978-0-12-802997-8.00016-5

21 Rades D, Dunst J and Schild SE: A new scoring system to predicting the survival of patients treated with whole-brain radiotherapy for brain metastases. Strahlenther Onkol 184: 251255, 2008. PMID: 18427755. DOI: 10.1007/s00066-008-1831-5

22 Dziggel L, Segedin B, Podvrsnik NH, Oblak I, Schild SE and Rades D: Validation of a survival score for patients treated with whole-brain radiotherapy for brain metastases. Strahlenther Onkol 189: 364-366, 2013. PMID: 23519358. DOI: 10.1007/ s00066-013-0308-3 